20

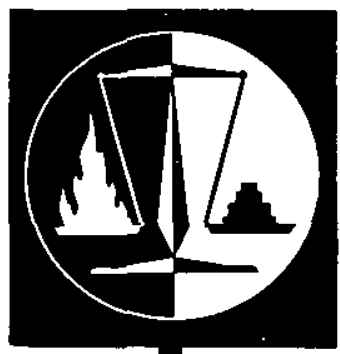

Fire Research Note No 1022

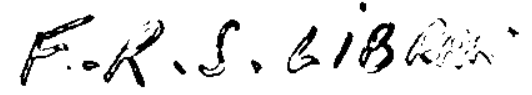

THE LIBRARY

FIRE RESEATCHI STATION

DOREHAPAWCOD MESTS.

NOAFAFR.N 1022

FLASH POINTS OF MIXTURES OF FLAMMA BLE

AND NON-F LAMMA BLE LIQUIDS

by

P F Thorne

January 1975

FIRE

RESEARCH

a....

STATION 
Fire Research Station BORE HA MWOOD

Hertfordshire WD6 2BL

Tel: 019536177 
FLASH POINTS OF MIXTURES OF FLAMMABLE AND

NON-FLAMMABLE LIQUIDS

by

P F Thorne

SUMMARY

A theory relating the flash points of mixtures of flammable and non-flammable liquids with their composition, is shown to be in good agreement with experimental data.

Using this theory, a method for predicting flammability diagrams from flash point measurements is developed.

KEY WORDS Flash point; Flammability limits.

\section{Crown copyright}

This report has not been published and should be considered advance research information. No reference should be made to it in any publication without the written consent of the Head of Fire Research 
1. Introduction 1

2. Theory 2

2.1 Flash points of liquid mixtures 2

2.2 Construction of flammability diagram 8

3. Application of Theory 9

3.1 Data used ' 9

3.2 Treatment of the data 10

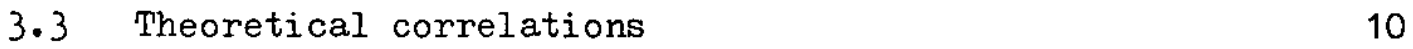

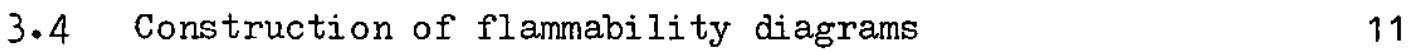

4. Discussion 11

4.1 Correlation of Flash Point Data 11

4.1.1 Mixtures of water miscible fuels with water 11

4.1.2 Mixtures of hydrocarbons with halogenated hydrocarbons 11

4.2 Flash Points and flammability diagrams 13

5. General Conclusions 14

6. Acknowledgment 14

7. References 14-15

Tables $\quad 16-19$

$\begin{array}{ll}\text { Appendix } 1 & 20\end{array}$

A.1.1 Experimental technique 20

A.1.2 Experimental results 20

A.1.3 Tables 21-23

Appendix 2 Thermodynamic Data 24

A.2.1 Calculation of activity coefficients using Van Laars equations 24

A.2.2 Calculation of vapour pressure 24-25 


\section{List of Symbols used}

\begin{tabular}{|c|c|}
\hline $\mathrm{p}_{f}^{\circ} \mathrm{p}_{\mathrm{a}}{ }^{\circ}$ & $\begin{array}{l}\text { saturated vapour pressures of pure liquid fuel and pure liquid } \\
\text { additive. }\end{array}$ \\
\hline$x_{f} x_{a}$ & mole fractions of fuel and additive in the liquid mixtures \\
\hline$\gamma_{f} \gamma_{a}$ & Activity coefficients of liquid fuel and additive \\
\hline$\alpha f \alpha_{a}$ & Activities of fuel and additive in the liquid $(\alpha=\gamma \cdot x)$ \\
\hline $\mathrm{P}_{\mathrm{T}}$ & Total pressure (atmospheric) \\
\hline $\mathrm{y}_{\mathrm{f}} \mathrm{y}_{\mathrm{a}}$ & mole fractions of fuel and vapour in the vapour in the vapour phase \\
\hline L & $\begin{array}{l}\text { Lower limit of flammability of the fuel vapour in air expressed as } \\
\text { mole (volume) fraction }\end{array}$ \\
\hline$T_{f}$ & Flash point temperature of pure liquid fuel \\
\hline $\mathrm{T}_{\mathrm{m}}$ & Flash point temperature of liquid mixture \\
\hline$\Delta \mathrm{H}_{\mathrm{f}}$ & Latent heat of vaporisation of liquid fuel \\
\hline $\mathrm{R}$ & Gas constant $8.314 \mathrm{~J} / \mathrm{moleK}$ \\
\hline $\mathrm{U}$ & $\begin{array}{l}\text { Upper limit of flammability of the fuel vapour in air expressed as } \\
\text { a mole (volume) fraction }\end{array}$ \\
\hline k & slope of line LL' in fig. 1 \\
\hline
\end{tabular}




\section{FLASH POINTS OF MIXIURES OF FLAMMABLE AND NON-FLAMMABLE LIQUIDS}

by

P F Thorne

\section{INTRODUCTION}

Flash point is an important property of a flammable liquid. The physical significance of 'Closed cup' and 'Open cup' flash points has been discussed by Burgoyne et al 5, 17 and it is clear that it is the 'Closed cup' flash point which has the greater relevance and practical applicability. In this note the term flash point means 'closed-cup flash point' as measured in a closed-cup flash point apparatus such as the Abel or Pensky-Martens.

Experimental values of flash point for pure liquid fuels are commonly available in the literature $7,13,14,15$ but often practical interest is focussed on the flash points of multicomponent liquid mixtures of the following types,

(1) mixtures in which all components are flammable

(2) mixtures in which some of the components are non-flammable;

the non-flammable components either

a) have no flame suppressing effect in the vapour phase or

b) exert a flame suppressing effect in the vapour phase The term 'flame suppressing effect' includes both physical (dilution, cooling) and chemical (inhibiting) mechanisms. The essential difference between types (2a) and (2b) mixtures is the magnitude of the partial vapour pressure of the non-flammable component(s) relative to the flammable component(s); it is low for (2a) mixtures. It will be shown later that the theory for (2b) mixtures also describes (2a) mixtures, but a rather more simple description of (2a) mixtures is available.

Examples of type (2) mixtures are the dilution of water miscible fuels with water to assist their safe disposal or effect extinction of a fire, and the addition to liquid hydrocarbon fuels of halogenated hydrocarbons to render them non-flammable or to effect an extinction. The addition of sufficient non-flammable material to prevent re-ignition of a flammable 
liquid spill fire following a successful extinction, is an important particular example.

Other mixtures of practical interest which may involve flammable and non-flammable liquids are paints and adhesives; such mixtures are also frequently encountered in the chemical process industry.

Type (1) mixtures have been discussed by, for example, Affens ${ }^{19}$ who has presented a theoretical basis for the prediction of their flash points. Type (2a) mixtures have been considered by Uehara ${ }^{6}$ but the theory of type (2b) mixtures has apparently not been considered. This note develops a theory which predicts the flash points of two-component type (2) (a) and (b) mixtures. In this note the relationship between flashpoints and limits of flammability is discussed and, bearing in mind the relative ease with which flash point measurements can be made as compared with those for flammability limits, the possibility of using flashpoint measurements to construct a flammability diagram is considered.

\section{THEORY}

\subsection{Flash points of liquid mixtures}

The 'closed-cup' flash point of a liquid fuel can be regarded as the temperature at which the vapour pressure of the fuel results in a concentration of fuel vapour above the liquid surface equal to the lower limit of flammability of the fuel vapour in air 5,10 .

There are of course, a number of differences in apparatus parameters and experimental conditions between flash point and flammability limit determinations, and these are summarised in Table 1. In the limit apparatus flame propagates upwards from a larger source of ignition than in the flash point apparatus. In the limit apparatus, the test mixture is premixed. In the flash point apparatus the composition of the vapour at the igniting source depends upon the liquid temperature and the rate of diffusion of vapours away from the liquid surface. 
Conditions are, therefore, somewhat more favourable for flame propagation, initially at least, in the limit apparatus than in the flash point apparatus. However, whereas in the limit apparatus flame is required to propagate a substantial distance from the source of ignition, in the flashpoint apparatus flame has only to propagate a relatively small distance for a 'positive' result.

The flash point so defined is a 'lower' value. An 'upper' flash point can be similarly defined by reference to the upper flammability limit.

The effect of the addition of a second (miscible) liquid will depend upon the volatility of the added liquid with respect to that of the fuel and on any flame suppressing effect the additive may have in the vapour phase.

In general, the addition to a liquid fuel of a second miscible liquid will depress the partial vapour pressure of the liquid fuel by dilution of the liquid phase.

The partial vapour pressure of the fuel vapour, $p_{f}$, is given by

$$
\begin{aligned}
p_{f}=x_{f} p^{o} f & \text { if the mixture is an 'ideal' } \\
& \text { solution and obeys Raoult's Law, }
\end{aligned}
$$


but $p_{f}=y_{f} P_{T}$

therefore $\mathrm{y}_{\mathrm{f}}=\frac{\alpha_{\mathrm{f} \mathrm{p}_{\mathrm{f}}}{ }^{\circ}}{\mathrm{P}_{\mathrm{T}}}$

The composition of the vapour phase will be $\mathrm{y}_{\mathrm{f}}$ of fuel vapour and $\left(1-y_{f}\right)$ of other components. If the volatility of the liquid additive is low relative to that of the liquid fuel, i.e. $P_{f}^{0} \gg P_{a}^{0}$ or the partial vapour pressure of the additive in the liquid mixture is relatively low, i.e. $\alpha_{f} p_{f}^{0} \gg \alpha_{a} p_{a}^{0}$ (or $p_{f} \gg p_{a}$ ) then the component $\left(1-y_{f}\right)$ will be essentially air and at the flash point of the liquid mixture $\left(T_{m}\right)$ the concentration of the fuel vapour will be the lower limit of flammability of the fuel vapour in air (L).

$$
\text { i.e. } \quad \alpha_{f}=\frac{L P_{T}}{p_{f}^{o}}
$$

Since the variation of $\mathrm{p}_{\mathrm{f}}$ with temperature will be known, from published vapour pressure/temperature data, equation (1) represents an implicit relationship between the flash point of a liquid mixture and its composition.

Strictly, the value of $L$ should be for the actual flash point rather than the standard temperature at which flammability limits are normally determined.

Zabetakis $^{2}$ gives a correlation for $L$ with temperature which indicates that over the range of temperature of interest in this note $(+70$ to $-30^{\circ} \mathrm{C}$ ) the maximum error incurred by the assumption that $\mathrm{L}$ is constant, is 4 per cent.

If an explicit correlation between vapour pressure and temperature such as the Antoine equation is adopted then an explicit relationship between flashpoint and composition can be derived. The Antoine equation is:

$$
\log \mathrm{p}^{\circ}=\mathrm{A}-\frac{\mathrm{B}}{\mathrm{T}+\mathrm{C}} \quad \mathrm{T} \text { is in }{ }^{\circ} \mathrm{C}
$$

Equation (1) can be written $L P_{T}=\alpha_{f} P_{f}^{0}$

$$
\text { When } \quad \alpha_{f}=1 \quad \text { (i.e. pure fuel) }
$$$$
\log p_{f}^{0}=A-\frac{B}{T_{f^{+}} C} \text { where } T_{f} \text { is in }{ }^{\circ} \mathrm{C}
$$ 


$$
\begin{aligned}
& \text { when } \alpha_{f}<1 \\
& \log \mathrm{p}_{f}{ }^{\circ}=\mathrm{A}-\frac{\mathrm{B}}{\mathrm{T} m+\mathrm{C}} \text { where } \operatorname{Trn} \text { is in }{ }^{\mathrm{O}} \mathrm{C} \\
& \therefore \quad A-\frac{B}{T_{f}+C}=\log \alpha_{f}+A-\frac{B}{T m}+C \\
& \underset{\mathrm{Tm}}{\operatorname{or}} \frac{1}{\mathrm{C}}=\frac{1}{\mathrm{~B}} \log \alpha_{f}+\frac{1}{\mathrm{~T}_{\mathrm{f}}+\mathrm{C}}
\end{aligned}
$$

If the Antoine equation which gave the best correlation of vapour pressure data always had a value for the constant $C$ of 273 then equation (1A) would assume a more convenient form, namely:

$$
\frac{1}{\mathrm{~T} m}=\frac{1}{\mathrm{~B}} \log X_{f}+\frac{1}{\mathrm{~T}_{\mathrm{f}}} \text { where } \mathrm{Tm} \text { and } \mathrm{T}_{\mathrm{f}} \text { are in }{ }^{\circ} \mathrm{K}
$$

However, this is not usually the case (see Appendix 2) and therefore equation 1 is of limited value.

An alternative explicit relationship can be derived as follows:

Take logs of equation (1) and differentiate w.r.t.T

$$
\frac{\mathrm{d} \ln \alpha_{f}}{d \mathrm{~T}}=\frac{-\mathrm{d} \ln \mathrm{p}_{\mathrm{f}}}{\mathrm{dT}}
$$

Now, a useful approximate form of the Clausius Clapeyronequation is

$$
\frac{\mathrm{d} \ln \mathrm{p}_{\mathrm{f}}{ }_{\mathrm{f}}}{\mathrm{dT}}=\frac{\Delta \mathrm{H}_{\mathrm{f}}}{\mathrm{RT}}
$$

$$
\text { therefore } \quad \frac{\mathrm{d} \ln \alpha}{\mathrm{dT}}=\frac{-\Delta \mathrm{H}_{\mathrm{f}}}{2}
$$

Strictly, latent heat of vaporisation, $\left(\Delta \mathrm{H}_{f}\right)$ is a function of temperature but can be regarded as constant over small temperature changes.

A correlation by Watson ${ }^{21}$ enables the error incurred by assuming constant at the value for $25^{\circ}$, to be estimated. For the temperature range of interest $\left(70\right.$ to $-30^{\circ} \mathrm{C}$ ) the maximum estimated error is 9 per cent.

Integrating

$$
\int_{1}^{2} d \ln \alpha=-\int_{1}^{2} \frac{\Delta H_{f}}{R T^{2}} d T
$$




$$
\ln \left[\frac{\alpha_{1}}{\alpha_{2}}\right]=-\frac{\Delta H_{f}}{R}\left[\frac{1}{T_{2}}-\frac{1}{T_{1}}\right]
$$

Let

$$
\alpha_{2}=1 \text { i.e. pure liquid fuel }
$$

$\mathrm{T}_{2}=\mathrm{T}_{f}$ the flash point of pure liquid fuel

$\alpha_{1}=\alpha_{f}$ activity of fuel in any liquid mixture

$\mathrm{T}_{1}=\mathrm{T}_{\mathrm{m}}$ the flash point of any liquid mixture

$$
\begin{aligned}
& \frac{1}{T_{m}}=\frac{R}{\Delta H_{f}} \ln \alpha_{f}+\frac{1}{T_{f}} \\
& \frac{1}{T_{m}}=2.303 \frac{R}{\Delta H_{f}} \log \alpha_{f}+\frac{1}{T_{f}}
\end{aligned}
$$

A plot of $\frac{1}{T_{m}}$ v. $\log \alpha_{f}$ will be a straight line of slope 2.303R/ $\Delta \mathrm{H}_{f}$, the intercept at $\alpha_{f}=1$ being the flash point of pure fuel, $\mathrm{T}_{\mathrm{f}}$.

Uehara $^{6}$ derives an equation similar to equation (3) for type (2a) mixtures.

If, however, the liquid additive is relatively volatile or the partial vapour pressure of the additive in the liquid mixture is significant, the modification of flash point by the additive will, in addition to the effect of dilution of the liquid phase discussed above, depend upon the flame suppressing effect of the additive vapour in the vapour phase.

The magnitude of the flame suppressing effect is represented by the amount by which the lower limit is increased by the addition of the additive vapour. Fig.1 shows the main features of a conventional flammability diagram. The lower and upper limits of flammability are $\mathrm{L}$ and $\mathrm{U}$ respectively. The increase in the lower limit on addition of additive vapour is shown as a straight line. Although this part of the flammability envelope for some additive/fuel/air systems is somewhat non-linear, inspection of published flammability diagrams ${ }^{1,2}$ confirms that a straight line approximation is acceptable. This line has been extrapolated on Fig. 1 for illustration, and is marked LL'. The slope (k) of this line is the measure of the magnitude of the flame suppressing 
effect of the additive in the vapour phase. The higher the value of $k$, the less flame suppressing effect is seen. Very high values of $k$ are associated with an almost non-existent increase in the lower limit on addition of additive vapour whilst a marked increase in lower limit by additives which exert a substantial flame suppressing effect results in low values of $\mathrm{k}$.

Some typical values of $\mathrm{k}$ for vapours of non-flammable liquids and some non-flammable gases are shown in Table 2 .

The equation of line LL on the flammability diagram Fig.1 is:

$$
\mathrm{y}_{\mathrm{a}}=\mathrm{k}\left(\mathrm{y}_{\mathrm{f}}-\mathrm{L}\right)
$$

This can be written

$$
\frac{\gamma_{a} x_{a} p_{a}^{0}}{p_{T}}=k\left(\frac{\alpha_{f} p_{f}^{0}}{p_{T}}-L\right)
$$

which, on rearrangement gives

$$
\alpha_{f}=\frac{\gamma_{a} p_{a}^{*}+k L P_{r}}{\frac{\gamma_{a}}{\gamma_{5}} p_{a}^{*}+k p_{f}^{*}}
$$

For an 'ideal' mixture $\gamma_{\mathrm{a}}=\gamma_{\mathrm{f}}=1$

$$
\text { and } \mathrm{x}_{\mathrm{f}}=\frac{\mathrm{p}_{\mathrm{a}}{ }^{\circ}+\mathrm{kLP}_{\mathrm{T}}}{\mathrm{p}_{\mathrm{a}}{ }^{\circ}+\mathrm{kp_{f }}}
$$

For a mixture which does not deviate substantially from ideality, $\alpha_{f} 2^{2} x_{f}$ except at low fuel concentrations therefore

$$
\alpha_{f}=x_{f}=\frac{p_{a}^{0}+k L p_{T}}{p_{0}^{0}+k p_{f}^{0}}
$$

Since the variation of $\mathrm{p}_{f}{ }^{\circ}$ and $\mathrm{p}_{\mathrm{a}}{ }^{\circ}$ with temperature will be known, from published vapour pressure/temperature data, equation (6) represents an implicit relationship between the flashpoint of a liquid mixture and its composition. For a particular fuel/additive/air system, $k, L P_{T}$ and $T_{f}$ will be known. For a number of temperatures between $T_{f}$ and $60^{\circ} \mathrm{C}$ (say) $\mathrm{p}_{\mathrm{f}}{ }^{\circ}$ and $\mathrm{p}_{\mathrm{a}}{ }^{\circ}$ are determined from published vapour pressure data. The composition of the mixture having flash points equal to the temperatures chosen can then be calculated. 
If the volatility of the additive is low, or the additive has little flame suppressing effect in the vapour phase, i.e. $k$ is large (as discussed above) so that $k L P_{T} \gg p_{a}{ }^{\circ}$ and $k p_{f}^{0} \gg p_{a}^{0}$ then equation (6) reduces to equation (1).

Since $\mathrm{p}_{\mathrm{f}}{ }^{\circ}$ and $\mathrm{p}_{\mathrm{a}}{ }^{\circ}$ are readily calculable by the Antoine equation (see above), equation (6) is an implicit relationship between the flash point of a liquid mixture and its composition.

If the additive has a low volatility or has little flame suppressing effect in the vapour phase, i.e. $k$ is large enough for $k_{\mathrm{LPP}} \gg \mathrm{p}_{\mathrm{a}}{ }^{0}$ and $\mathrm{kp}_{\mathrm{f}}^{\circ} \gg \mathrm{p}_{\mathrm{a}}^{\circ}$ then equation (6) reduces to equation (1).

\subsection{Construction of flammability diagram}

A corollary of the preceding argument is the thesis that the measurements of the flash point of mixtures of a flame and inhibiting liquid will enable a flammability diagram for that system to be constructed. Fig.1 shows the usual flammability diagram. The line $A B$ represents the change in composition, with temperature, of the vapour in equilibrium with a liquid mixture of a certain composition. The line has been drawn arbitrarily but actually represents mixtures in which the fuel is the more volatile component. The temperature increases from $A$ towards $B$ and it is assumed that the composition of the liquid remains constant. As the temperature increases from the initial point $A$ the conventional closed cup flash point will be reached and constitute one point on the lean limit curve of the flammability diagram. However, as the temperature is increased from $A$ towards $B$, the liquid will exhibit 'flash points' until the point $B$ is reached, when no 'flash' will be observable since the vapour mixture will be too rich to propagate flame in the cup. The point $B$, which has been called the 'upper flash point' (Ref.5), will constitute one point on the rich leg of the flammability diagram.

A number of curves similar to $A B$ can be envisaged each corresponding to a liquid mixture of different composition, the uppermost curves containing most inhibiting liquid. The line CD corresponds to liquid mixture too rich in inhibitor to exhibit a flash point. However, at the temperature corresponding to point $D$ the vapour mixture in the cup on issuing from, and mixing with air just outside the cup will be diluted along the line DO which passes through the flammability envelope. A flammable mixture will be formed which will burn outside the cup. These anomalous 
'ignitions' have been discussed by Gerstein and Stine ${ }^{20}$.

The curve EF corresponds to an important limiting mixture. Only one flashpoint $\left(\mathrm{E}^{\prime}\right)$ is exhibited by this mixture, and the line EF will be a tangential to the flammability diagram. Following a small further increase in temperature, the point $F^{\prime}$ will be reached giving rise to burning outside the cup, no flash being exhibited, as discussed above.

If, for a particular system the curve EF approached the flammability envelope at a shallow angle, then burning outside the cup could occur at the flashpoint of the mixture.

Clearly then, by making flashpoint measurements on a number of suitable liquid mixtures, it is possible to construct a flammability envelope. In order to do so, of course, it is essential that vapourliquid equilibrium data for the system be known. The co-ordinates $\left(y_{a}, y_{f}\right)$ of the points on the flame envelope can then be calculated from the composition of the liquid mixtures viz.

$$
\begin{aligned}
& y_{a}=\gamma_{a} x_{a} p_{a}^{0} / p_{T} \\
& y_{f}=\gamma_{f} x_{f} p_{t}^{0} / p_{T}
\end{aligned}
$$

The validity of a flame envelope constructed in this way will be discussed later.

\section{APPLICATTON OF THEORY}

\subsection{Data Used}

The theoretical relationships developed in the previous section will be applied to the systems listed below. Where an experimental determination is indicated, a description of the method and the detailed results are presented in Appendix 1.

Some additional data published by Friedrich ${ }^{9}$ for n-heptane/carbon tetrachloride has not been included. Friedrich's flashpoint $\left(T_{f}\right)$ for n-heptane $\left(-8^{\circ} \mathrm{C}\right)$ appears to be anomalous. 


\begin{tabular}{|l|c|c|}
\hline \multicolumn{1}{|c|}{ System } & $\begin{array}{r}\text { Experimental } \\
\text { Determinations }\end{array}$ & $\begin{array}{c}\text { Reference to } \\
\text { published data }\end{array}$ \\
\hline $\begin{array}{l}\text { Methanol-water } \\
\text { Ethanol-water }\end{array}$ & - & 6 \\
$\begin{array}{l}\text { Acetone-water } \\
\text { n-hexane-carbon } \\
\text { tetrachloride } \\
\text { n-heptane-carbon } \\
\text { tetrachloride } \\
\text { n-octane-carbon } \\
\text { tetrachloride } \\
\text { n-hexane-dichlorodi- } \\
\text { fluoromethane }\end{array}$ & $\checkmark$ & 7 \\
\hline
\end{tabular}

\subsection{Treatment of the data}

Activities $(\alpha)$ have been calculated from mole fractions $(x)$ and activity coefficients $(\gamma)$ which were computed using the Van Laar equations. The values used for the constants in the Van Laars equations are given in Appendix 2. The activity of the single mixture of $n$-hexane/dichlorodifluoromethane was calculated from the vapour pressure data in ref (5).

In Figs.2 to 5 the reciprocal of the flashpoint $\left(\frac{1}{\mathrm{Tm}}, \mathrm{K}^{-1}\right)$ for each mixture has been plotted against the activity of the fuel $\left(\alpha_{f}\right)$. Ethanol/water mixtures are showin in Fig.2, methanol/water and acetone/ water mi.xtures in Fig.3. Mixtures of n-heptane, n-hexane and n-octane with carbon tetrachloride are shown in Fig.4, and the single value for n-hexane (dichlorodifluoromethane) is shown in Fig. 5 .

\subsection{Theoretical correlations}

Theoretical correlations for a number of fuel/additive systems have been computed from equations (1) (3) and (6). The values of the various constants in these equations were as follows:

$$
\begin{aligned}
& \text { L as shown in Table } 3 \\
& \mathrm{~T}_{\mathrm{f}} \text { " " Table } 3 \\
& \text { k " " Table } 2 \\
& \mathrm{P}_{\mathrm{T}} \quad 760 \mathrm{~mm} \mathrm{Hg} \\
& p_{f}{ }^{\circ} \quad p_{a}{ }^{\circ} \quad \text { computed from the Antoine equation using } \\
& \text { the constants shown in Appendix } 2 . \\
& \Delta H_{f},\left(2.303 R / \Delta H_{f}\right) \text { as shown in Table } 4 \text {. }
\end{aligned}
$$


Theoretical correlations of $\frac{1}{T}$ with $f$ have been computed for the systems listed in Table 5. These correlations are shown plotted in Figs.2 to 5. The systems shown in Fig.5 were chosen to represent a wide range of values of $k$ and $\mathrm{p}_{\mathrm{a}}{ }^{\circ}$.

\subsection{Construction of flammability diagrams}

The lower limit segment of the flammability diagram has been constructed for the n-hexane-, n-heptane- and n-octane- carbon tetrachloroide systems as described in section 3.4 above. Sample calculations for the system n-heptane-carbon tetrachloride are shown in Table 6. The computed values of $y_{a}$ and $y_{f}$ are plotted in Fig.6. A complete flammability diagram for n-hexane-carbon tetrachloride, taken from Coleman ${ }^{4}$, is also shown.

For each set of data, a linear regression line has been computed and is also shown. The equations of these lines are:

$$
\begin{array}{lc}
\text { n-hexane-carbon tetrachloride } & y_{a}=7.86\left(y_{f}-1.09\right) \\
r & =0.90 \\
\text { n-heptane-carbon tetrachloride } & y_{a}=10.69\left(y_{f}-1.195\right) \\
r & =0.98 \\
\text { n-octane-carbon tetrachloride } & y_{a}=11.58\left(y_{f}-0.87\right) \\
r & =0.97
\end{array}
$$

where $r$ is the correlation coefficient.

\section{DISCUSSION}

\subsection{Correlation of Flash Point Data}

4.1.1 Mixtures of water miscible fuels with water

Figs.2 and 3 show the experimental data and theoretical correlations for mixtures of methanol, ethanol and acetone with water. The correlations of equations (1) and (6) are similar and are represented by a common line. This is because, for these three fuels, $k$ is high (40 to 70) and thus equation (6) (and (4)) reduce to equation (1).

In all three cases, the experimental data is correlated by equation (3) but less well by equation (1).

\subsubsection{Mixtures of hydrocarbons with halogenated hydrocarbons}

Fig. 4 shows the experimental data and theoretical correlations for mixtures of $n$-hexane, $n$-heptane and $n$-octane with carbon tetrachloride. The theoretical correlations are from equations (3) and (6), equation (1) being inappropriate for reasons already 
discussed. As expected equation (3) generally does not correlate well with data, it being concerned solely with dilution of the liquid phase and not including inhibition in the vapour phase. There is, however, a partial correlation of equation (3), particularly at higher values of $\alpha_{f}$, with the data for n-hexane-carbon tetrachloride solutions. In this case, the inhibitor, carbon tetrachloride (BP $76.7^{\circ} \mathrm{C}$ ), is less volatile than the fuel, n-hexane (BP $68.7^{\circ} \mathrm{C}$ ). In the other two cases the fuels, n-heptane (BP $98.4^{\circ} \mathrm{C}$ ) and n-octane (BP $125.7^{\circ} \mathrm{C}$ ) are less volatile than the inhibitor. Fuel-rich n-hexane-carbon tetrachloride mixtures behave as type 2(a) mixtures simply because of the low value of $\mathrm{p}_{\mathrm{a}}$ relative to $\mathrm{p}_{\mathrm{f}}$. This is illustrated by the proximity of the correlation of equation (3) to that of equation (6) for $\alpha_{f}>0.4$. Fuel-lean mixtures (e.g. $\quad \alpha_{f}<0.25$ ) behave as type 2(b) mixtures.

The correlation of the data by equation (6) is considered to be satisfactory in view of:

1) The value of $\mathrm{k}(=9)$ for $n$-hexane is assumed for $n$-heptane and n-octane.

2) The equilibrium data (Van Laar constants) for n-heptane is assumed for n-hexane and n-octane.

3) Equation (6) is an approximation of equation (4)

4) The composition of the liquid in the cup was assumed not to change significantly during the course of a determination.

It would be preferable to have available better data for $\mathrm{k}$ and the Van Laar constants to calculate the theoretical correlation from equation (4) using an iterative technique, and to check the liquid composition by a suitable analytical technique, on reaching the flash point temperature.

Fig. 5 shows theoretical correlations from equation ( 3$)^{\circ}$ and equation (6) for mixtures of n-hexane with carbon tetrachloride, bromochloromethane, trichlorofluoromethane, dichlorodifluoromethane and bromochlorodifluoromethane. Equation (3) for reasons previously discussed, yields a single correlation for all mixtures. The only experimental data, apart from the n-hexane-carbon tetrachloride mixtures shown in Fig. 4 and discussed above, is for a single mixture of $n$-hexane and dichlorodifluoromethane, which has been calculated from data given in ref (5). This is in reasonable agreement with the theoretical correlation. 


\subsection{Flash points and flammability diagrams}

The lower limit curve of a flammability diagram constructed from flashpoint data, as discussed in section 3.4, is shown for n-hexanecarbon tetrachloride in Fig.6(a) and for n-heptane and n-octane with carbon tetrachloride in Fig.6(b). A complete flammability diagram for n-hexane-carbon tetrachloride, taken from Coleman ${ }^{4}$, is superimposed on Fig.6(a). Flammability diagrams for the other two systems are not available.

The open points in Figs.6(a) and 6(b) correspond to the calculated composition of the vapour phase in equilibrium with the liquid mixture which exhibited the highest flashpoint, at a temperature $1^{\circ} \mathrm{F}\left(0.6^{\circ} \mathrm{C}\right)$ above that flash point, i.e. the condition under which continued burning outside the cup was observed.

These open points correspond to the point $\mathrm{F}^{\prime}$ in Fig.1. The closed point immediately adjacent to each open point corresponds to the point $E^{\prime}$ in Fig.1 A line joining the two, when extrapolated each side corresponds to the line EF in Fig.1 The 'peak value' will lie between the two points. The values of 'peak value' for the three systems studied, taken from Fig.6 are:

\begin{tabular}{|c|c|c|c|}
\hline n-hexane- & & achloride & 7.5 per cent \\
\hline$n$-heptane & $"$ & $"$ & 10.2 per cent \\
\hline n-octane & $"$ & $"$ & 11.8 per \\
\hline
\end{tabular}

The published value for n-hexane-carbon tetrachloride4 is 9.7 per cent. There appear to be no published data for n-heptane and n-octane with carbon tetrachloride.

It appears, from these results, that the composition of lower limit mixtures predicted from flash point measurements are similar to those measured using the standard flammability limit apparatus, but that predicted peak values may be lower than those measured in the limit apparatus.

It is of interest to note that differences in limit apparatus dimensions can affect both lower limits and 'peak values' (see for example ref (1) page 51). The smaller dimensions of the flash point apparatus apparently only affect the 'peak value'. Further study is required to resoive this aspect.

The work described in this note indicates that flash point measurements together with the appropriate vapour liquid equilibrium data can provide a quick and convenient method for estimating, with some accuracy, the lower limit limb of a flammability diagram. 
'Upper' flash points have not been studied here but it is of great interest to know whether such measurements would enable the upper limit limb of a flammability diagram to be predicted satisfactorily. If so, the the point of intersection might be expected to correspond to the 'peak value' for the system.

\section{GENERAL CONCLUSIONS}

Although there are differences between the flash point and flammability limit apparatuses (as discussed in section 2.1) the validity of a theory which enables flash points of liquid mixtures to be predicted from a knowledge of certain properties of the flammability diagram, and allows the lower limit limb of a flammability diagram to be constructed from flash point measurements, is shown to be supported by experimental evidence.

Because of the relative ease with which flash point measurements can be made compared with those for flammability limits, a potentially more convenient method for constructing flammability diagrams has been shown to exist. The method does, however, depend upon a knowledge of the appropriate vapour-liquid equilibrium data.

\section{ACKNOWLEDGMENT}

Miss S.P. Benson made the flash point measurements for acetone-water mixtures.

A. Moorehouse made the flash point measurements for mixtures of $n$-hexane, n-heptane and n-octane with carbon tetrachloride and chlorobromomethane.

\section{REFERENCES}

1. COWARD, H.F. and JONES, G.W. 'Limits of Flammability of Gases and Vapours' Bulletin 503 (1952) United States Bureau of Mines.

2. ZABETAKIS, M.G. 'Flammability Characteristics of Combustible Gases and Vapours' Bulletin 627 (1965) United States Bureau of Mines

3. ELKINS, G.H.J. Fire Research Note 327 (1957)

4. COLEMAN, E.H. Technical Booklet No.11. (1852)

Fire Protection Association

5. BURGOYNE, J.H. and WILLIAMS-LEIR, G. 'Inflammability of Liquids'

Fuel 28 (1949) 145.

6. UEHARA, Y. 'Flash Points of a Diluted Fuel and the Inhibiting Effect of

Some Halomethanes'. Report of Fire Research Institute of Japan No.29 (1969) p.17. 
7. 'Fire Protection Guide on Hazardous Materials'

National Fire Protection Association 1966

8. BROOKE, M. Chemical Analyst 40 (1951) 92

9. FRIEDRICH, M. V F D B Zeitschrift 10 (1) (Jan 1961) p.12

10. MULLINS, B.P. 'Combustion Résearches and Reviews 1957 '

Butterworths Scientific Publications London 1957 p.69

11. BOUBLIK T., FRIED V. and HALA, E.

'The Vapour Pressures of pure substances' Elsevier 1973

12. HALA, E., WICHTERLE, I., POLAK, J. and BOUBLIK, T.

'Vapour Liquid Equilibrium Data at Normal Pressures'

13. Chemical Engineers Handbook Ed. Perry

Third Edition p.528 McGraw Hill 1950

14. 'Fire and Related Properties of Industrial Chemicals'

Fire Protection Association, 4th Edition 1972

15. Handbook of Industrial Loss Prevention

Factory Mutual Engineering Corporation. McGraw Hill 1967

16. Flash Point by the Abel Apparatus IP170/70

Institute of Petroleum 1970

17. BURGOYNE, J.H. ROBERTS, A.F. and ALEXANDER, J.

The Significance of Open Flash Points. J. Inst. Pet.

23 (526) $1967 \quad 338-341$

18. BUTLER, R.M., COOKE, G.M., LUKK, G.G. and JAMESON, B.G.

Prediction of Flashpoints of Middle Distillates

Ind. Eng. Chem. 48 (4) 1956 808-812

19. AFFENS, W.A. and MCLAREN, G.W.

Flammability Properties of Hydrocarbon Solutions in Air

$\mathrm{J}$ Chem and Eng Data 171972 482-488

20. GERSTEIN, M. and STINE, W.B. Anomalies in Flash Points of

Mixtures of Halogenated Hydrocarbons and Flammable Liquids

Paper WSS/C1 70-20 presented at meeting of US Combustion

Institute, Norwood, Mass. 1970.

21. WATSON, Ind. Eng. Chem. 35 (1943) 398 
Table 1

Comparison of flammability limit and flash point apparatuses

\begin{tabular}{|l|c|c|}
\hline & $\begin{array}{c}\text { Flammability } \\
\text { limit apparatus }\end{array}$ & $\begin{array}{c}\text { Abel flash point } \\
\text { apparatus }\end{array}$ \\
\hline $\begin{array}{l}\text { Volume of flammable } \\
\text { vapour mixture }\left(\mathrm{cm}^{3}\right)\end{array}$ & 2945 & 35 \\
Height (mm) & 1500 & 18 \\
Diameter (mm) & 50 & 50 \\
Ignition source & $\begin{array}{l}\text { Spark, typically } \\
\text { about } 15 \text { or flame }\end{array}$ & Small, $4 \mathrm{~mm}$, flame \\
Direction of flame & Upwards & Down and sideways \\
propagation & Normally 25 ${ }^{\circ} \mathrm{C}$ & $\begin{array}{l}\text { The actual flash } \\
\text { point of the liquid } \\
\text { mixture }\end{array}$ \\
\hline
\end{tabular}

Table 2

Some typical values of the constant ' $k$ '

\begin{tabular}{|l|c|c|c|}
\hline \multicolumn{1}{|c|}{ Additive } & Fuel & $k$ & Ref \\
\hline Bromochlorodifluoromethane & n-hexane & 1.8 & 3 \\
Bromochloromethane & n-hexane & 9 & 4 \\
Carbon tetrachloride & n-hexane & 9 & 4 \\
Dichlorodifluoromethane & n-hexane & 10 & 5 \\
Water & Methanol & 70 & 2 \\
Water & Ethanol & 40 & 2 \\
Water & Methane & 28 & 2 \\
Carbon dioxide & Methane & 25 & 1 \\
Nitrogen & Methane & 110 & 1 \\
Helium & Methane & $\rightarrow \infty$ & 1 \\
\hline
\end{tabular}

\section{Notes:}

(1) Value of $k$ for the system n-hexane - trichlorofluoromethane assumed to be 10 .

(2) Values of $\bar{k}$ for mixtures of $n$-heptane and n-octane with halogenated hydrocarbons assumed to be the same as for n-hexane mixtures. 
Table 3

\begin{tabular}{|c|c|c|c|c|c|c|c|c|c|c|c|}
\hline \multirow[t]{2}{*}{ Fuel } & \multicolumn{2}{|c|}{$\begin{array}{c}\text { Experimental } \\
\text { values of } \\
\text { L } \% \mathrm{v} / \mathrm{v}\end{array}$} & \multicolumn{2}{|c|}{$\begin{array}{l}\text { Calculated } \\
\mathrm{T}_{f} \text { from } \mathrm{L}\end{array}$} & \multicolumn{5}{|c|}{ Experimental values of $\mathrm{T}_{\mathrm{f}}$} & \multicolumn{2}{|c|}{$\begin{array}{l}\text { Values used } \\
\text { in calculations }\end{array}$} \\
\hline & $\operatorname{Ref} 1$ & Ref 2 & Ref 1 & Ref 2 & Ref 13 & Ref 14 & Ref 7 & $\operatorname{Ref} 15$ & $\begin{array}{l}\text { This } \\
\text { work }\end{array}$ & $\stackrel{\mathrm{T}_{\mathrm{f}}}{\mathrm{Eqn} 3}$ & L \\
\hline Methanol & 7.5 & 6.7 & 10.4 & 8.5 & 11 & 10 & 11 & 12 & - & 11 & 7.5 \\
\hline Ethanol & 4.0 & 3.3 & $14 \cdot 1$ & 11.1 & 12 & 13 & 13 & 12 & - & 13 & 4.0 \\
\hline Acetone & 3.0 & 2.6 & -19.5 & -21.7 & -18 & -18 & -18 & -18 & - & -18 & 3.0 \\
\hline n-hexane & 1.2 & 1.2 & -26.4 & $-26 \cdot 4$ & -26 & -22 & -22 & -22 & -26 & -26 & 1.2 \\
\hline n-heptane & 1.2 & 1.05 & -3.47 & -5.5 & -4 & -4 & -4 & -4 & -3.9 & -4 & 1.2 \\
\hline$n$-octane & 1.0 & 0.95 & 14.8 & 14 & 13 & 13 & 13 & 13 & 13.3 & 13 & 0.95 \\
\hline
\end{tabular}

Table 4

Values of $\Delta \mathrm{H}_{\mathrm{f}}$ and the slope of equation (3) for some liquid fuels

\begin{tabular}{|c|c|c|}
\hline Fuel & $\Delta \mathrm{H}_{f}$ & Slope $\frac{2.303 \mathrm{R}}{\Delta \mathrm{H}_{f}}$ \\
\hline Methanol & $3.82 \times 10^{4}$ & $5.01 \times 10^{-4}$ \\
Ethanol & $4.23 \times 10^{4}$ & $4.53 \times 10^{-4}$ \\
Acetone & $3.28 \times 10^{4}$ & $5.84 \times 10^{-4}$ \\
n-Hexane & $3.14 \times 10^{4}$ & $6.07 \times 10^{-4}$ \\
n-Heptane & $3.65 \times 10^{4}$ & $5.24 \times 10^{-4}$ \\
n-Octane & $4.13 \times 10^{4}$ & $4.62 \times 10^{-4}$ \\
\hline
\end{tabular}


Table 5

Mixtures for which theoretical correlations have been calculated

\begin{tabular}{|c|c|c|c|}
\hline Fig No" & Sys tem & $\begin{array}{l}\text { Equations } \\
\text { us ed }\end{array}$ & Comment \\
\hline 2 & Ethanol-water & (1) and (3) & \multirow{2}{*}{$\begin{array}{l}\text { Correlation from } \\
\text { equation (6) is } \\
\text { essentially } \\
\text { coincident with } \\
\text { that from } \\
\text { equation (1) }\end{array}$} \\
\hline 3 & $\begin{array}{l}\text { Methanol-water } \\
\text { Acetone-water }\end{array}$ & (1) and (3) & \\
\hline 4 & $\begin{array}{l}n \text {-hexane } \\
\text { n-heptane }\left\{\begin{array}{l}\text { carbon } \\
\text { tetra- } \\
\text { n-octane }\end{array} \text { chloride }\right.\end{array}$ & (3) and (6) & \multirow{2}{*}{$\begin{array}{l}\text { Correlation from } \\
\text { equation ( } 3 \text { ) } \\
\text { represents limiting } \\
\text { conditions for all } \\
\text { mixtures }\end{array}$} \\
\hline 5 & $\begin{array}{l}\text { n-hexane and } \\
\text { 1. chlorobromomethane, } \\
\text { 2. trichlorofluoro- } \\
\text { methane, } \\
\text { 3. dichlorodifluoro- } \\
\text { methane, } \\
\text { 4. bromochloro } \\
\text { difluoromethane, } \\
\text { 5. also carbon } \\
\text { tetrachloride } \\
\text { (repeated for } \\
\text { comparison) }\end{array}$ & (3) and (6) & \\
\hline
\end{tabular}


Table 6

Calculation of flammability limit curve from flashpoint data for n-heptane - carbon tetrachloride mixtures

\begin{tabular}{|c|c|c|c|c|c|c|c|c|}
\hline${ }^{\mathrm{T}}$ & $\mathrm{x}_{f}$ & $x_{a}$ & $\gamma_{f}$ & $\gamma_{a}$ & $\left(\begin{array}{c}\mathrm{P}_{\mathrm{f}}^{\mathrm{O}} \\
(\mathrm{mm} \mathrm{Hg})\end{array}\right.$ & $\begin{array}{c}\mathrm{P}_{\mathrm{a}}^{\circ} \\
(\mathrm{mm} \mathrm{Hg})\end{array}$ & 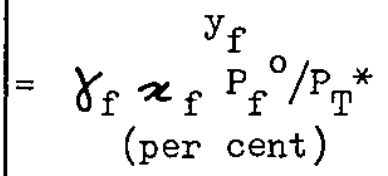 & $=\gamma_{\mathrm{a}} x_{(\mathrm{per} \text { cent })}^{\mathrm{y}_{\mathrm{a}}} \mathrm{P}_{\mathrm{a}}^{\circ} / \mathrm{P}_{\mathrm{T}}^{*}$ \\
\hline-3.9 & 1 & 0 & 1. & 1 & 8.87 & 27.10 & 1.16 & 0 \\
\hline-1 & 0.93 & 0.07 & $1:$ & 1.008 & 10.66 & 31.83 & 1.30 & 0.295 \\
\hline 0 & 0.86 & 0.14 & 1 & 1.02 & 11.36 & 33.60 & 1.28 & 0.635 \\
\hline 1 & 0.78 & 0.22 & 1.003 & 1.035 & 12.08 & 35.50 & 1.25 & 1.07 \\
\hline 5.6 & 0.7 & 0.30 & 1.008 & 1.05 & 15.94 & 45.22 & 1.48 & 1.88 \\
\hline 8.9 & 0.6 & 0.40 & 1.013 & 1.07 & 19.31 & 33.51 & 1.54 & 3.02 \\
\hline 11 & 0.5 & 0.50 & 1.026 & 1.09 & 21.76 & 59.40 & 1.47 & 4.25 \\
\hline $18 \cdot 3$ & 0.4 & 0.60 & 1.048 & 1.105 & 32.38 & $84 \cdot 30$ & 1.78 & 7.35 \\
\hline 21.7 & 0.38 & 0.62 & 1.053 & 1.11 & 38.65 & 98.55 & 2.04 & 8.92 \\
\hline 23.9 & 0.36 & 0.64 & 1.060 & 1.11 & 43.22 & 108.78 & 2.17 & 10.17 \\
\hline 24.5 & 0.36 & 0.64 & 1.060 & 1.11 & 44.55 & 111.88 & 2.24 & 10.46 \\
\hline
\end{tabular}

* $\mathrm{P}_{\mathrm{T}}$ taken to be $760^{\circ} \mathrm{mm} \mathrm{Hg}$

$f$ continued burning 


\section{A.1.1. Experimental technigue}

Closed-cup flash points were measured using the Abel apparatus according to the method described by the Institute of Petroleum ${ }^{16}$, except in the case of acetone-water mixtures for which the following modification was adopted for those particular mixtures flashing below room temperature. The cup, complete with lid and stirrer, was precooled by submerging it up to the flange in a bed of powdered solid carbon dioxide. The heating of the sample was effected simply by standing the cup, shielded from draughts, on an insulating pad in the laboratory. In this modification, the temperature of the liquid sample was measured ky a chromel/alumel thermocouple.

Liquid samples were prepared by weighing, the liquid componerts being precooled to redice evaporation losses. The prepared mixtures were stored in sealed containers at $-20^{\circ} \mathrm{C}$ until required.

With the hydrocarbon/carbon tetrachloride mixtures, it was noticed that, on approaching the flash point, the initially blue/green test flame enlarged, becoming yellow. It was also noted that, for those mixtures containing the highest concentrations of carbon tetrachloride which did exhibit a flash point, continued heating and application of the test flame beyond the flash point resulted in continued burning outside the cup rather than the expected 'flashing' inside the cup.

The highest concertration of acetone in water for which a flash point was measured was 40 per cent by volume $\left(x_{f}=0.14\right)$. Mixtures containing more acetone than this showed signs of crystallisation at temperatures above the flash point, making an experimental determination uncertain.

\section{A.1.2. Experimental results}

The results of the experimental measurements are giver in Tables A1, $A 2$ and $A 3$ as the mole fraction of the fuel component $\left(x_{f}\right)$ and the corresponding flash point $\left(T_{m}\right)$. Where appropriate, mixtures which exhibited continued burning outside the cup are indicated.

The treatment of these results and their correlation with theory is described in Section 3.

Table A3 contains results obtained for mixtures of n-hexane, n-heptane and $r$-octane with chlorobromomethane. These results, however, are not considered further since equilibrium data is not available for these systems. 
A.1.3

Table A1

Sunmary of flash point results for mixtures of acetone and water

\begin{tabular}{|l|c|c|}
\hline $\begin{array}{c}\text { Mole fraction } \\
\text { of acetone }\end{array}$ & $\begin{array}{c}\text { Measured flash } \\
\text { point temperature } \\
(\mathrm{O})\end{array}$ & $\frac{1}{\mathrm{~T}}\left(\mathrm{~K}^{-1}\right) \times 10^{3}$ \\
\hline 0.005 & 46 & 3.14 \\
0.0127 & 27 & 3.33 \\
0.0264 & 15.5 & 3.47 \\
0.0413 & 9 & 3.55 \\
0.0576 & 3 & 3.62 \\
0.095 & -2 & 3.69 \\
0.14 & -7 & 3.76 \\
\hline
\end{tabular}


Table A2

Summary of flash point results for n-hexane $\mathrm{n}$-heptane and $\mathrm{n}$-octane with carbon tetrachloride

\begin{tabular}{|c|c|c|c|}
\hline $\begin{array}{c}\text { Mole fraction } \\
\text { of fuel } \\
\mathrm{x}_{\mathrm{f}}\end{array}$ & $\begin{array}{l}\text { Measured flash } \\
\text { point temperature } \\
\mathrm{T}(\mathrm{c})\end{array}$ & $\frac{1}{T}\left(K^{-1}\right) \times 10^{3}$ & $\begin{array}{c}\text { Fuel activity } \\
\alpha_{f}\end{array}$ \\
\hline $\begin{array}{l}\text { n-hexane } \\
1.0 \\
0.88 \\
0.80 \\
0.64 \\
0.50 \\
0.40 \\
0.30 \\
0.20 \\
0.175 \\
0.16 \\
0.155\end{array}$ & $\begin{array}{l}-26 \\
-25 \\
-22 \\
-18 \\
-16 \\
-12.8 \\
-10.6 \\
0 \\
7.8 \\
11.0 * \\
\text { No flash }\end{array}$ & $\begin{array}{c}4.05 \\
4.03 \\
3.98 \\
3.92 \\
3.89 \\
3.84 \\
3.81 \\
3.66 \\
3.56 \\
3.52 \\
-\end{array}$ & $\begin{array}{l}1.0 \\
0.88 \\
0.804 \\
0.664 \\
0.538 \\
0.44 \\
0.348 \\
0.246 \\
0.218 \\
0.202 \\
0.198\end{array}$ \\
\hline $\begin{array}{c}\text { n-heptane } \\
1.0 \\
0.93 \\
0.86 \\
0.78 \\
0.70 \\
0.60 \\
0.50 \\
0.40 \\
0.38 \\
0.36 \\
0.35\end{array}$ & $\begin{array}{l}-3.9 \\
-1 \\
0 \\
1 \\
5.6 \\
8.9 \\
11.0 \\
18.3 \\
21.7 \\
23.9^{*} \\
\text { No flash }\end{array}$ & $\begin{array}{c}3.72 \\
3.68 \\
3.66 \\
3.65 \\
3.59 \\
3.55 \\
3.52 \\
3.43 \\
3.39 \\
3.37 \\
-\end{array}$ & $\begin{array}{l}1.0 \\
0.93 \\
0.86 \\
0.782 \\
0.706 \\
0.608 \\
0.513 \\
0.419 \\
0.400 \\
0.382 \\
0.372\end{array}$ \\
\hline $\begin{array}{l}\text { n-octane } \\
1.0 \\
0.84 \\
0.79 \\
0.67 \\
0.575 \\
0.55 \\
0.53\end{array}$ & $\begin{array}{c}13.3 \\
19.4 \\
21.7 \\
28.3 \\
33.9 \\
36.0^{*} \\
\text { No flash }\end{array}$ & $\begin{array}{c}3.49 \\
3.42 \\
3.39 \\
3.32 \\
3.26 \\
3.24 \\
-\end{array}$ & $\begin{array}{l}1.0 \\
0.84 \\
0.792 \\
0.677 \\
0.585 \\
0.561 \\
0.541\end{array}$ \\
\hline
\end{tabular}

*Continued burning outside the cup occurred $0.6^{\circ} \mathrm{C}\left(1^{\circ} \mathrm{F}\right)$ higher 
A. 1.3

Table A3

Summary of flash point results for n-hexane n-heptane and n-octane with bromochloromethane

\begin{tabular}{|c|c|c|}
\hline $\begin{array}{c}\text { Mole fraction } \\
\text { of fuel } \\
x_{f}\end{array}$ & $\begin{array}{c}\text { Measured flash } \\
\text { point temperature } \\
\mathrm{T}(\mathrm{c})\end{array}$ & $\frac{1}{\mathrm{~T}}\left(K^{-1}\right) \times 10^{3}$ \\
\hline $\begin{array}{l}\text { n-hexane } \\
1.0 \\
0.93 \\
0.86 \\
0.78 \\
0.69 \\
0.60 \\
0.50 \\
0.40 \\
0.30 \\
0.28 \\
0.26\end{array}$ & $\begin{array}{l}-26 \\
-25 \\
-23 \\
-22 \\
-20 \\
-17 \\
-15 \\
-11 \\
-5.6 \\
1^{*} \\
\text { No flash }\end{array}$ & $\begin{array}{l}4.05 \\
4.03 \\
4.00 \\
3.98 \\
3.95 \\
3.91 \\
3.88 \\
3.82 \\
3.74 \\
3.68 \\
-\end{array}$ \\
\hline $\begin{array}{l}\text { n-heptane } \\
1.0 \\
0.92 \\
0.84 \\
0.75 \\
0.71 \\
0.66 \\
0.60 \\
\text { Measurements } \\
\text { incomplete }\end{array}$ & $\begin{array}{r}-3.9 \\
-0.6 \\
1.11 \\
3.9 \\
7.8 \\
9.4 \\
12.8\end{array}$ & $\begin{array}{l}3.72 \\
3.67 \\
3.65 \\
3.61 \\
3.56 \\
3.54 \\
3.50\end{array}$ \\
\hline $\begin{array}{l}\text { n-octane } \\
1.0 \\
0.89 \\
0.79 \\
0.76 \\
0.75\end{array}$ & $\begin{array}{l}13.3 \\
17.2 \\
20.6 \\
27.8^{*} \\
\text { No flash }\end{array}$ & $\begin{array}{l}3.49 \\
3.445 \\
3.43 \\
3.32 \\
-\end{array}$ \\
\hline
\end{tabular}

* Continued burning outside the cup occurred $0.6^{\circ} \mathrm{C}\left(1^{\circ} \mathrm{F}\right)$ higher 
APPENDIX 2

THERMODYNAMIC DATA

A.2.1. Calculatition of activity coefficients_using Van Laars equations

The activity coefficients $1, \quad 2$ of a two component liquid mixture can be calculated from the Van Laar equations

$$
\text { ie } \begin{aligned}
\log _{10} \gamma_{1} & =c_{1} /\left[1+\left(x_{1} c_{1} / x_{2} c_{2}\right)\right]^{2} \\
\log _{10} \gamma_{2} & \left.=c_{2} /\left[\begin{array}{lll}
1+\left(x_{2}\right. & c_{2} / x_{1} & c_{1}
\end{array}\right)\right]^{2}
\end{aligned}
$$

where $x_{1}, x_{2}$ are the mole fractions of the two components and $c_{1}, c_{2}$ are constants for the mixture values of $c_{1}, c_{2}$ for the mixtures used in the examples are:

\begin{tabular}{|c|c|c|c|c|}
\hline Component 1 & Component 2 & $\mathrm{C}_{1}$ & $\mathrm{C}_{2}$ & Ref. \\
\hline Ethanol & Water & 0.67 & 0.42 & 13 \\
\hline Methanol & Water & 0.25 & 0.20 & 13 \\
\hline Acetone & Water & 0.89 & 0.65 & 13 \\
\hline n-Heptane* & Carbon tetrachloride & 0.2164 & 0.0618 & 12 \\
\hline
\end{tabular}

*The same values of $\mathrm{C}_{1}$ and $\mathrm{C}_{2}$ have been assumed for the systems $n$-hexane/carbon tetrachloride and n-octane/carbon tetrachloride

\section{A.2.2. Calculation of vapour pressure}

Vapour pressures were calculated from the Antoine equation which is of the form

$$
\begin{aligned}
& \log _{10} P=A-\frac{B}{T+C} \quad P \text { in m } H g \\
& T \text { in oC }
\end{aligned}
$$

Values of the constants $A, B$ and $C$ have been published ${ }^{11}$ and are given below for the Iiquids considered in this note. 


\begin{tabular}{|l|c|c|c|}
\hline \multicolumn{1}{|c|}{ Liquid } & A & B & C \\
\hline Methanol & 8.08097 & 1582.271 & 239.726 \\
\hline Ethanol & 8.1122 & 1592.864 & 226.184 \\
\hline Acetone & 7.11714 & 1210.595 & 229.664 \\
\hline n-Hexane & 6.88555 & 1175.817 & 224.867 \\
\hline n-Heptane & 6.90253 & 1267.828 & 216.823 \\
\hline n-Octane & 6.91874 & 1351.756 & 209.100 \\
\hline $\begin{array}{l}\text { Carbon } \\
\text { tetrachloride }\end{array}$ & 6.87926 & 1212.021 & 226.409 \\
\hline $\begin{array}{l}\text { Bromochloro- } \\
\text { methane }\end{array}$ & 6.49606 & 942.267 & 192.587 \\
\hline $\begin{array}{l}\text { Bromochloro- } \\
\text { difluoromethane }\end{array}$ & 6.83998 & 935.632 & 240.330 \\
\hline
\end{tabular}




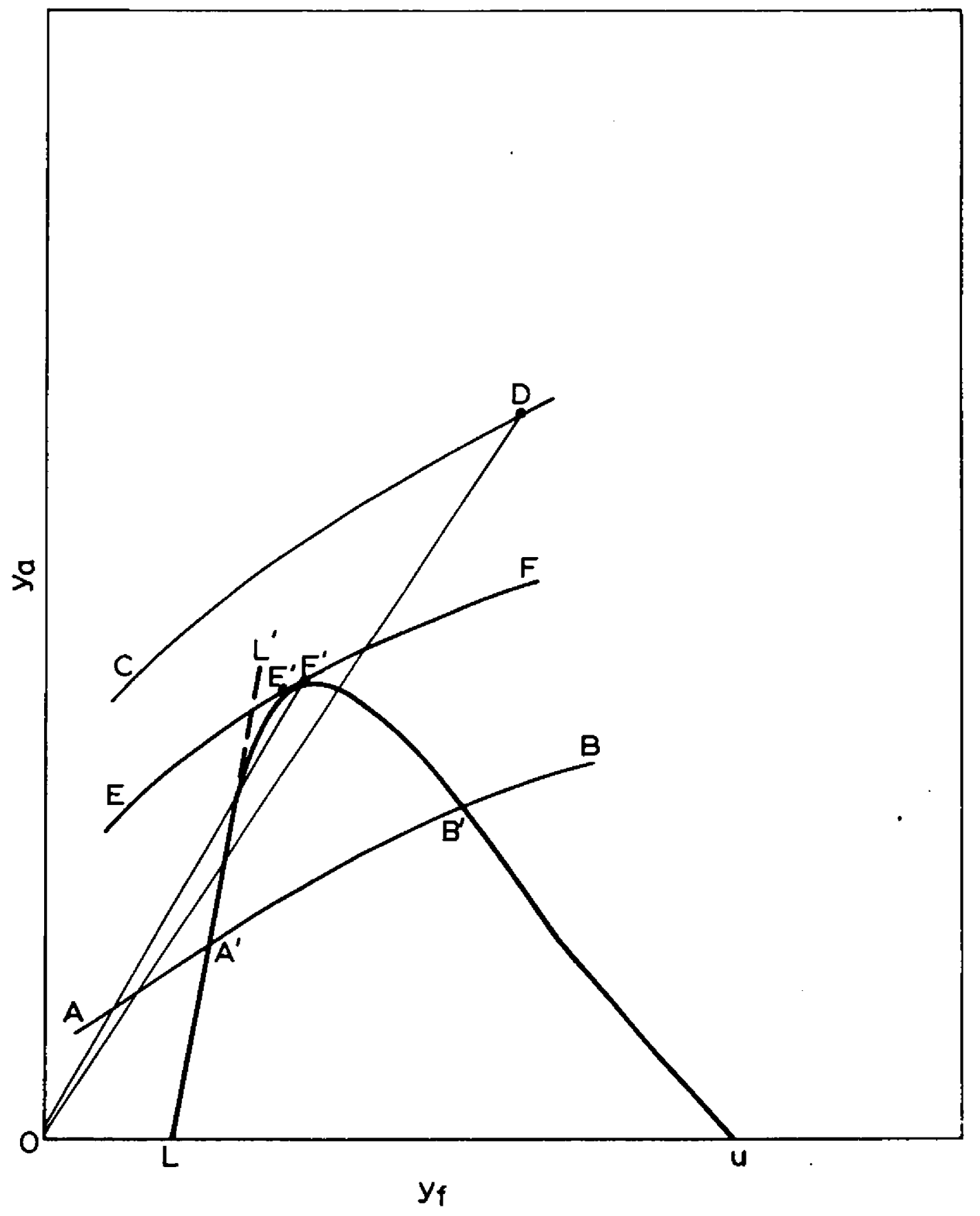

Figure1 Flammability diagram 


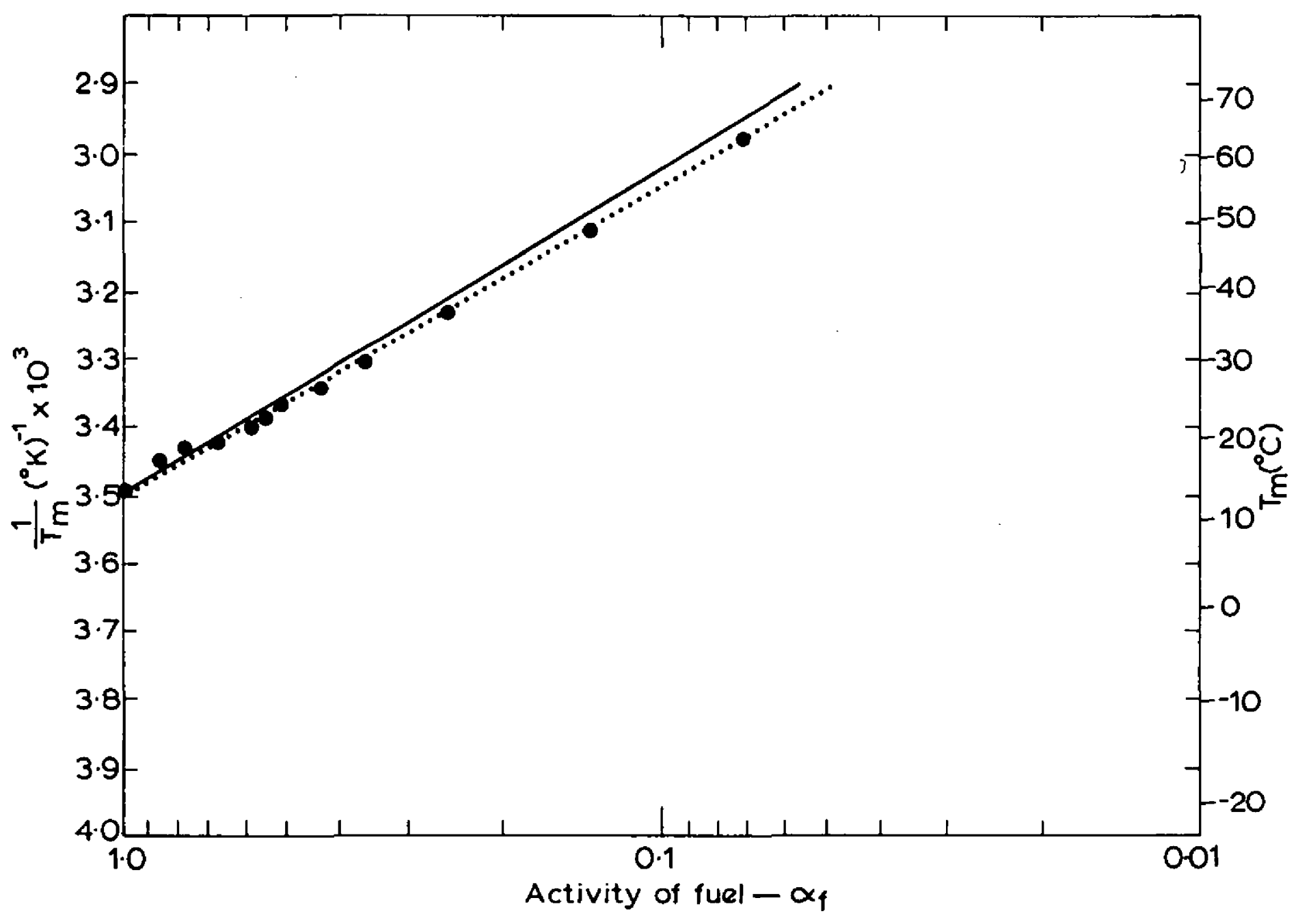

Theoretical prediction from equation ( 3 )

Theoretical prediction from equation (1) and (6)

- Experimental results-Ref(7)

Figure 2 Flash point-composition correlations for ethanol/water mixtures 


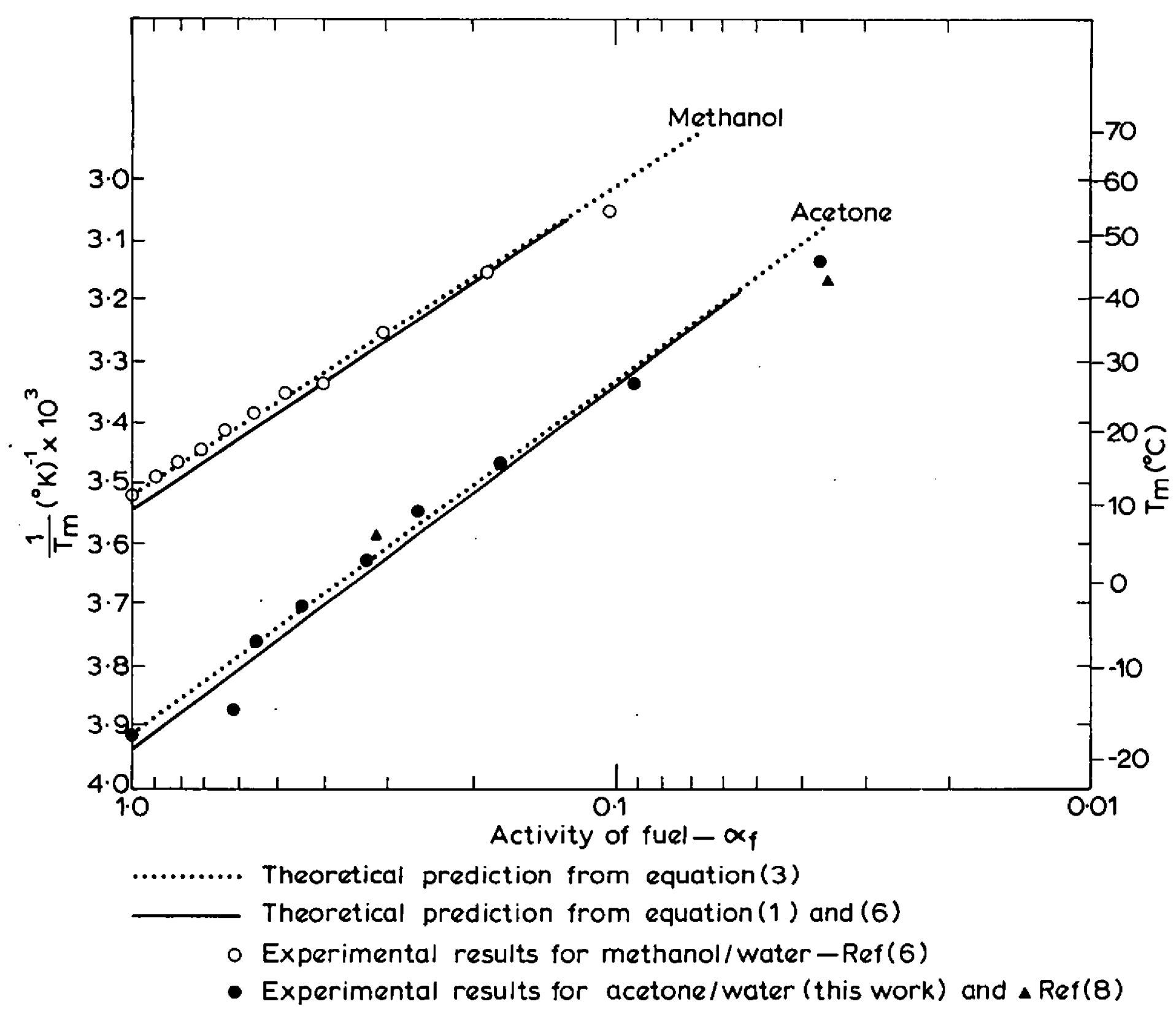

Figure 3 Flash point - composition correlations for methanol/water and acetone/water mixtures 


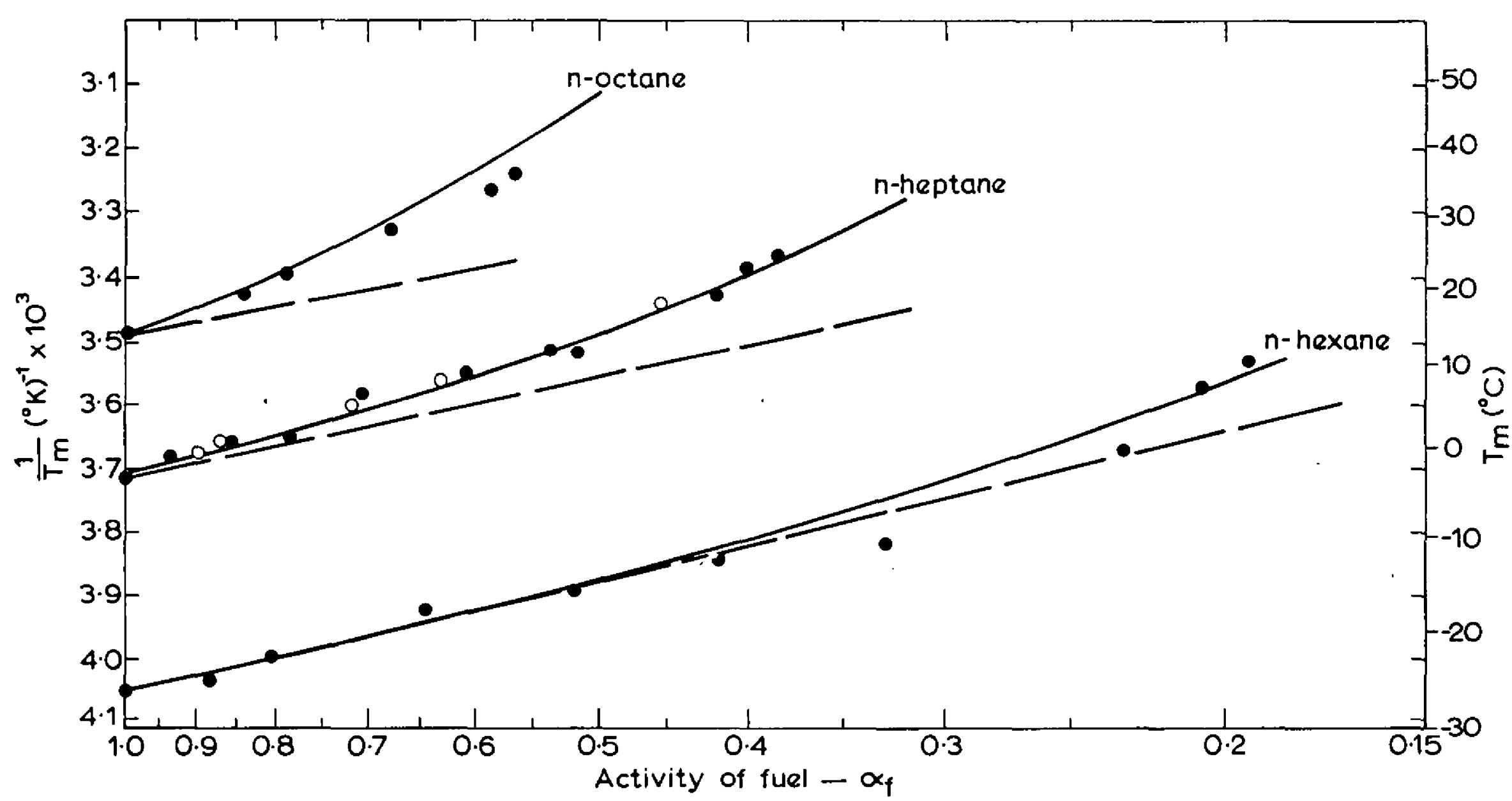

Theoretical prediction from equation (3)

Theoretical prediction from equation (6)

- Experimental results - this work

- Experimental results - Ref (6)

Figure 4 Flash point-composition correlations for $n$-hexane/carbon tetrachloride, n-heptaine/ carbon tetrachloride and n-octane/carbon tetrachloride mixtures 


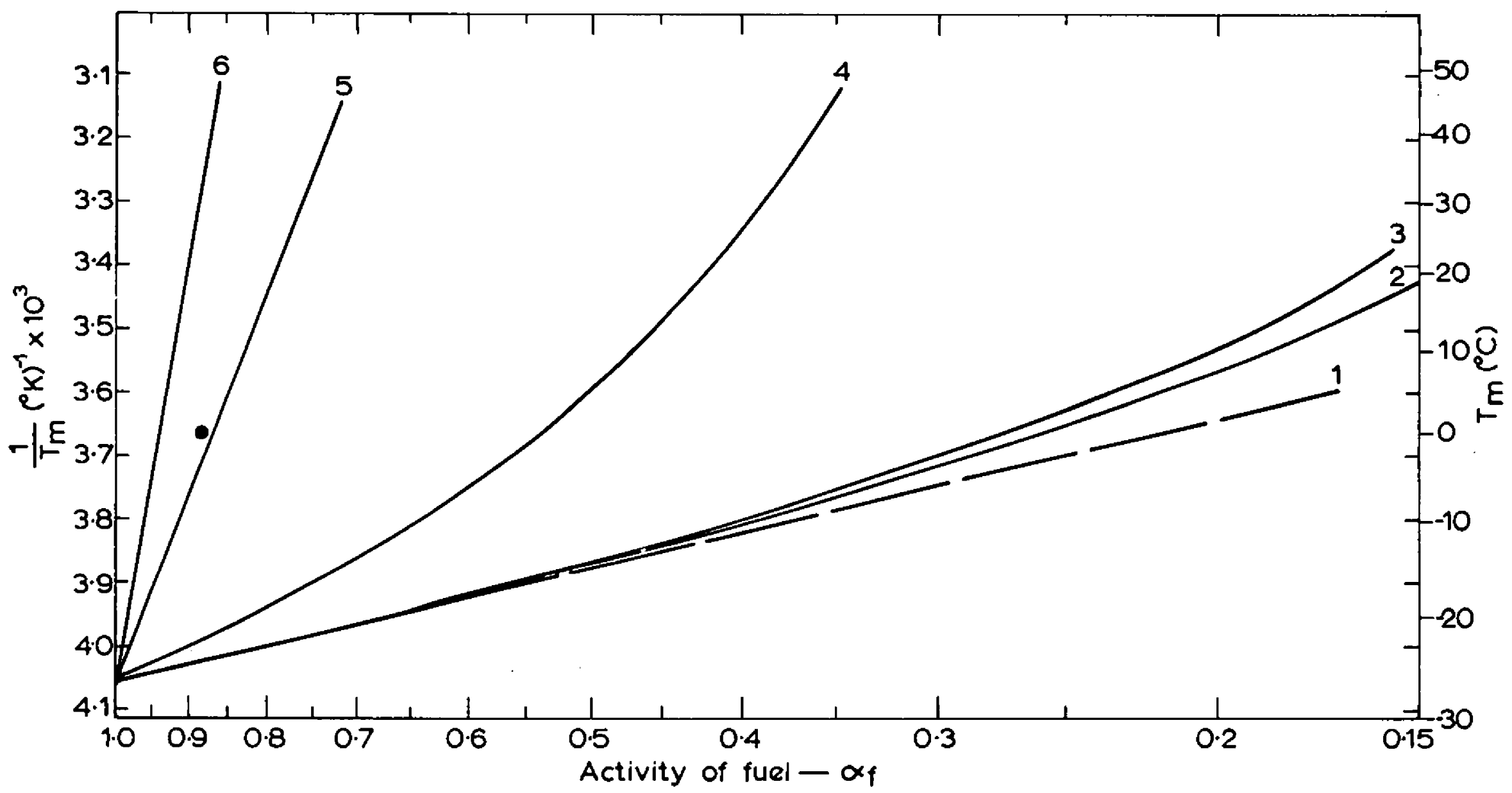

1 For all mixtures, from equation (3)

2 Mixtures with carbon tetrachloride, from equation(6)

3 Mixtures with chlorobromomethane, from equation (6)

4 Mixtures with trichlorofluoromethane, from equation (6)

5 Mixtures with dichlorodifluoromethane, from equation(6) expt'l point from Ref(5)

6 Mixtures with bromochlorodifluoromethane, from equation (6)

Figure 5 Flash point-composition correlations for mixtures of $n$-hexane with various halogenated hydrocarbons - theoretical predictions 

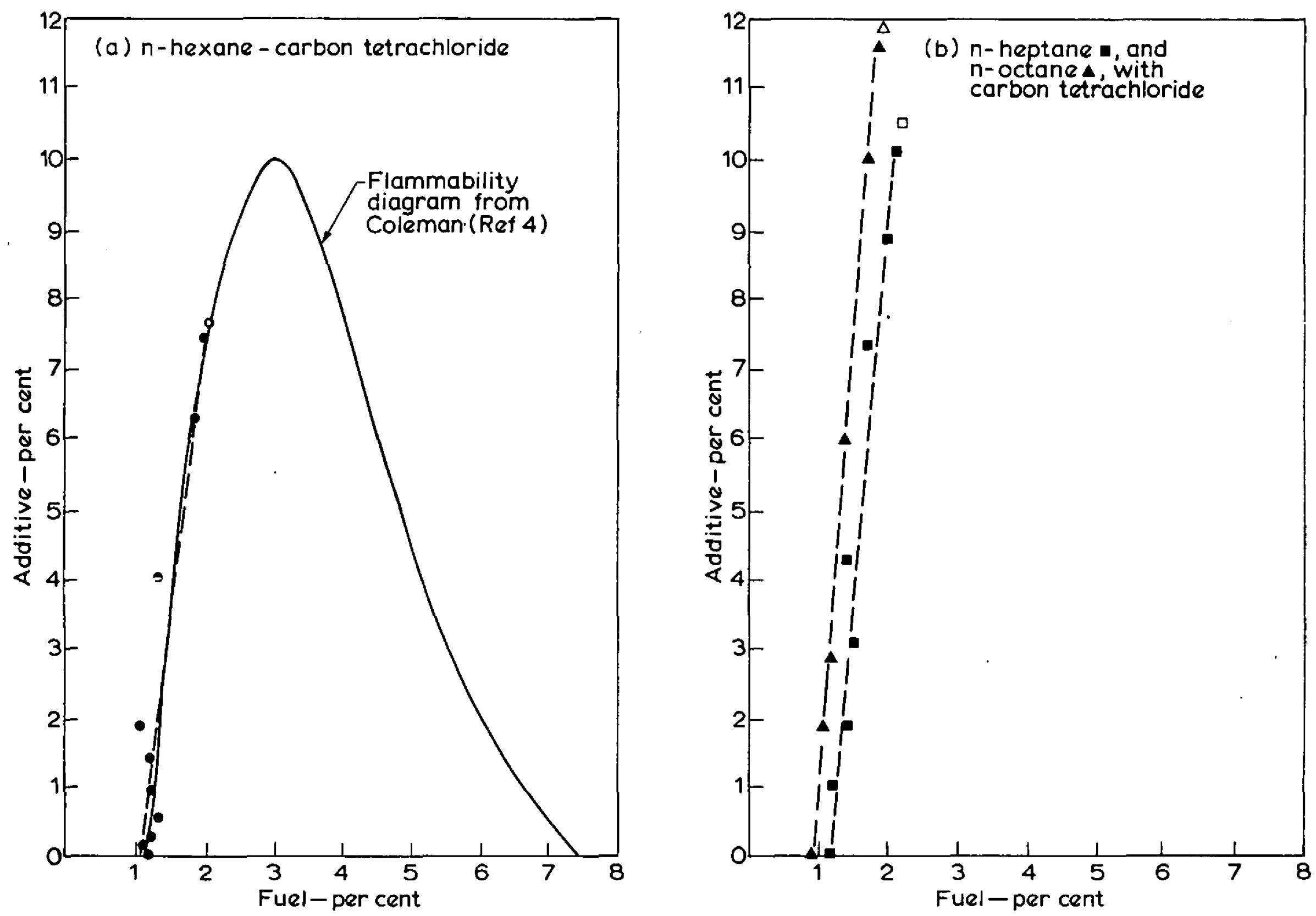

- _ - 'Least squares' linear regression lines

Figure 6 Lower limit flammability curves constructed from flash-point data 